\section{P3.34 CONGENITAL SYPHILIS IN THE STATE OF SÃO PAULO: "A PROBLEM THAT CONCERNS US ALL"}

Carmen Silvia Bruniera Domingues, Carmen Carla Gianna Luppi, Carmen Solange Chabu Gomes, Carmen Mariza Vono Tancredi, Carmen Maria Clara Gianna. STD and AIDS Referral and Training Centre - São Paulo State Department of Health, São Paulo - SP, Brazil

\subsection{6/sextrans-2017-053264.27}

Introduction To analyse congenital syphilis (CS) between 2007 and 2014, and case profile in 2014 in the state of São Paulo (SSP).

Methods Ecological descriptive study; sources: SINAN (cases) and Fundação Seade (live births-LB population).

Results 24684 cases of syphilis in pregnancy (PS) and 12479 of CS reported in the period. PS detection rate and CS incidence rate increased 2.8 times (3.5 to 9.9/1,000 LB) and 2.4 times (2.0 to 4.8/1,000 LB) in 2010 and 2014, respectively. There were 132 infant deaths and 1051 stillbirths and miscarriages by syphilis, about $9.5 \%(1,183)$ of total cases. In 2014 , $29 \%(870 / 2,989)$ of CS cases did not complete clinical and laboratory protocol (no long bone $\mathrm{x}$-ray or CSF) and 17\% $(499 / 2,989)$ did not comply with treatment protocol. About $20 \%(612 / 2,989)$ of mothers were $\leq 19$ years old, $75 \%$ $(2,244 / 2,989)$ underwent antenatal care (AN) and of these, $71 \% \quad(1,597 / 2,244)$ were diagnosed with syphilis. Although most mothers had access to AN diagnosis of syphilis during pregnancy, the vertical transmission chain was not interrupted. It is emphasised that $55 \%(1,632 / 2,989)$ of the mother's treatment was considered inadequate, because the sexual partner was not treated $(74 \%, 2,203 / 2,989)$.

Conclusion Albeit preventable, CS remains a public health problem with failures, especially during AN. Early diagnosis and treatment up to the 20th week of pregnancy can reduce fetal loss and prevent infant deaths. The case definition is sensitive considering the treatment of sexual partner in the mother's treatment classification. The public health challenge is to increase coverage and quality of $\mathrm{AN}$, expand diagnosis and treatment of women and sexual partners in primary care services, and prevent STDs, especially in vulnerable women. To identify determinants of transmission and foster interventions, CS cases have been investigated using specific protocols and discussed in regional and municipal committees. The SSP proposed using Mother and Child Mortality Committees to discuss the cases, given they have already been established and are operating regularly.

\section{P3.35 FREQUENCY OF HUMAN PAPILLOMAVIRUS AND GENOTYPES IN POPULATION ATTENDING A WOMEN'S CLINIC IN MONTERREY, MEXICO}

N Casillas-Vega, A Flores-Aréchiga, S Lozano-Quintanilla, F Pérez-Chávez, 'Llaca-Díaz J. Universidad Autónoma de Nuevo León, Monterrey, Mexico

10.1136/sextrans-2017-053264.272

Introduction: Human papillomavirus (HPV) is the most common viral infection of the reproductive tract. The aim is to determine the frequency of HPV and its genotypes in population that came to a Women's Clinic.

Methods HPV detection was performed in endocervial samples from 339 patients that came to woman clinical in the Hospital "Dr. José Eleuterio González“. DNA extraction was performed; After that, the $\beta$ globin gene was detected to validate the presence of epithelial cells in the sample; HPV was detected by the PCR technique and nucleic acid hybridization; 17 high-risk genotypes $(16,18,31,33,35,39,45,51,52$, $53,56,58,59,66,68,73$ and 82) and 17 low-genotypes (6, $11,26,40,42,54,55,61,62,64,67,69,70,71,81,83$ and 84).

Results The mean age of the population was 50 (range, 1889) years. Of the samples that were positive for the $\beta$ globin gene $(n=316) ; 7 \%(n=22)$ was positive for HPV. 18 HPV genotypes were detected; of which $65 \%(n=10)$ were at high risk. The most frequent genotypes were $16(n=4), 59(n=4)$, $51(n=3)$ and $42(n=3)$. In $77 \%(n=17)$ of the patients, high-risk genotypes were detected. In 59\% $(n=13)$ of the population a 1 genotype was detected, in 23\% $(n=5) 2$ genotypes and in $18 \%(n=4) 3$ genotypes.

Conclusions Of the 22 patients infected with HPV, 17 had been infected with at least one high-risk genotype. The most frequently detected genotypes were 16 and 59.

\section{P3.36 FREQUENCY AND GENOTYPES OF CHLAMYDIA TRACHOMATIS IN PATIENTS ATTENDING IN MEXICO AND CORRELATION WITH SOCIODEMOGRAPHIC, BEHAVIOURAL, AND BIOLOGICAL FACTORS}

N Casillas-Vega, A Flores-Aréchiga, S Lozano-Quintanilla, F Pérez-Chávez, J Llaca-Díaz. Universidad Autónoma de Nuevo León, Monterrey, Mexico

\subsection{6/sextrans-2017-053264.273}

Introduction Chlamydia trachomatis is the causative agent of the most common bacterial sexually transmitted infection worldwide. The aim of this study was to investigate the frequency and genotypes of C. trachomatis in patients attending an obstetrics and gynaecology clinic in Jalisco, Mexico and correlates them with risk factors.

Methods C. trachomatis detection was performed in endocervical samples from 662 patients by direct fluorescence assay (DFA) and two PCR assays that amplified the phospholipase $\mathrm{D}$ endonuclease superfamily (PRPHA) and OmpA genes. Positive samples were genotyped using PCR-restriction fragment length polymorphism assays. Sociodemographic, behavioural, and biological data were collected.

Results The mean age of the study population was 31 (range, 14-78) years. C. trachomatis positivity was detected by DFA in $16.7 \% \quad(\mathrm{n}=111)$, PRPHA gene amplification in $14.2 \%$ $(\mathrm{n}=94)$, and $O m p A$ gene amplification in $14.5 \%(\mathrm{n}=96)$ of the population. Eight C. trachomatis genotypes were detected: E (39.6\%), F (29.2\%), D (15.6\%), K (6.3\%), L2 (3.1\%), G, $\mathrm{J}$, and I (2.1\% each). C. trachomatis infection was associated with age, marital status, pregnancy, and hormonal contraceptive use (all $\mathrm{p}=0.01$ ); intrauterine device use and previous premature birth (both $\mathrm{p}=0.03$ ); C. trachomatis genotype $\mathrm{K}$ was more likely to be detected in women histories of $\geq 2$ sexual partners, genotype $\mathrm{F}$ in pregnant women, genotype L2 in women with PID, genotype D in women who had had infection during previous pregnancies, and genotype $\mathrm{E}$ was more likely in those with previous ectopic pregnancies and green vaginal discharge (all $\mathrm{p}=0.01)$.

Conclusions The frequency of C. trachomatis in our population was higher than previously reported worldwide, but within the range reported for Mexico. Genotype $\mathrm{E}$ was detected most frequently in the study population. Infection by C. trachomatis and C. trachomatis genotypes $\mathrm{K}, \mathrm{F}, \mathrm{D}$, and $\mathrm{E}$ was strongly associated with multiple sociodemographic, 